\title{
Detection of the Plasmodium falciparum Kelch-13 gene P553L mutation in sporozoites isolated from mosquito salivary glands in South-Central Vietnam
}

\author{
Yoshimasa Maeno ${ }^{1 *}$, Nguyen Tuyen Quang ${ }^{2}$, Richard Culleton ${ }^{3}$, Satoru Kawai ${ }^{4}$, Gaku Masuda ${ }^{5}$, Kaoru Hori ${ }^{1}$,
} Shusuke Nakazawa ${ }^{6}$ and Ron P. Marchand ${ }^{2}$

\begin{abstract}
Background: Plasmodium falciparum has developed resistance against artemisinin in Southeast Asia. Mutations in the P. falciparum Kelch-13 (Pfk13) gene are associated with artemisinin resistance in vitro and in vivo. We investigated the prevalence of mutations in PfK13 from sporozoite-stage parasites isolated from the salivary glands of Anopheles dirus mosquitoes.

Methods: Mosquitoes were caught by human-landing catches at two locations within the Khanh Phu commune, South-Central Vietnam. Identification of Anopheles species was performed based on morphological features and nucleotide sequence analysis. Sporozoite-infected salivary glands were stored on filter paper and at $4-6{ }^{\circ} \mathrm{C}$. A nested-PCR targeting the small subunit ribosomal RNA gene was used for Plasmodium species identification. Pfk13 was amplified by nested PCR, and subjected to nucleotide sequencing.

Results: Five of 33 P. falciparum sporozoite samples carried the P553L mutation at the PfK 13 locus. This mutation has been recorded previously in Vietnam, but not in Khanh Hoa province, were surveys of K13 polymorphism have not previously been carried out.
\end{abstract}

Conclusion: These results demonstrate the utility of mosquito-stage malaria parasite samples for studies on the molecular epidemiology of drug resistance.

Keywords: Plasmodium falciparum, Anopheles dirus, Sporozoite, Artemisinin resistance, K13-propeller gene, Vietnam

\section{Background}

Artemisinin-based combination therapy (ACT) against Plasmodium falciparum is currently the most common and effective first-line therapy in most malaria-endemic countries. Recently, however, clinical cases of artemisinin resistance have been reported from various countries in Southeast Asia [1-6] and Africa [7].

Genome-wide analysis of artemisinin resistance in $P$. falciparum has demonstrated that mutations in the propeller domain of the gene encoding the Kelch 13 (K13) protein $(P f k 13)$ are associated with delayed parasite clearance in vitro and in vivo $[8,9]$. In Southeast Asia, a number of mutations in the $P f k 13$ gene linked to artemisinin resistance have been identified, including C580Y, $\mathrm{Y} 493 \mathrm{H}, \mathrm{R} 539 \mathrm{~T}, \mathrm{I} 543 \mathrm{~T}$ and others. In Vietnam, the C580Y, P574L, V568G, P553L, I543T and Y493H mutations have been recorded, all from the Southern part of the country on the border with Cambodia [10].

In this report, we characterized the polymorphism at the Pfk13 locus using parasite DNA extracted from sporozoites isolated from the salivary glands of humanbiting Anopheles dirus mosquitoes in South-central Vietnam.

\footnotetext{
* Correspondence: ymaeno@fujita-hu.ac.jp

'Department of Virology and Parasitology, Fujita Health University School of Medicine, Toyoake, Aichi, Japan

Full list of author information is available at the end of the article
} 


\section{Methods}

Collection of mosquitoes was carried out through human-baited landing catches in and around the forest near Nga Hai village in the south of Khanh Phu commune, Khanh Vinh district, Khanh Hoa province, Vietnam. Collection of mosquitoes was carried out as previously described [11, 12] from January 2008 to October 2012. Mosquito collectors provide informed consent and were regularly screened for malaria and treated with ACT if a malaria infection was detected. Identification of Anopheles species was carried out based on morphological characteristics [13] and through analysis of nucleotide sequences [12]. Female mosquitoes were dissected and examined by microscopy for sporozoites. Sporozoite-infected salivary glands were stored on filter paper kept in closed vials at $4-6{ }^{\circ} \mathrm{C}$ until analysis [13].

Genomic DNA (gDNA) was extracted from preserved filter paper with sporozoite-positive salivary glands $[11,14]$. The $18 \mathrm{~S}$ rRNA gene-based nested PCR was used for the detection of $P$. falciparum and other Plasmodium species [12, 15]. Amplification of the Pfk13 gene was carried out by nested PCR as previously described [8], and the products sequenced with BigDye Terminator v3.1 Cycle Sequencing Premix Kit (ABI, Foster city, CA, USA). Sequencing products were run on an ABI/Hitachi 3130x1 Genetic Analyzer (ABI) and nucleotide sequences were analysed using Genetyx (Genetyx Corporation, Tokyo, Japan).

\section{Results and discussion}

A total of 11,464 female An. dirus (Figure 1) were captured; of these, 11,437 mosquitoes were dissected and the presence of sporozoites in salivary glands determined by microscopic examination. One hundred and sixtyeight (1.47\%) showed Plasmodium sporozoites infection (Table 1). Of the sporozoites infected mosquitoes, 152 out of 168 (90.5\%) were used for this study. By nested PCR analysis, 42 out of 152 stored sporozoite-positive mosquitoes $(27.6 \%)$ were identified as harbouring $P$. falciparum (Table 2).

Nucleotide sequencing was performed on the nested PCR amplified portion of $P f k 13$ (nucleotide positions 1279-2127) for 34 out of the $42 P$. falciparum sporozoite-positive mosquitoes, of which 33 were successfully assayed (Table 2). Single nucleotide polymorphisms (SNPs) with respect to the $P f k 13$ sequence of the 3D7 clone (PF3D7_1343700) were detected at low frequencies (Table 3). Synonymous mutations were not observed, and only a single non-synonymous mutation, P553L, was recorded. This mutation was present in 5 of the $33 \mathrm{P}$. falciparum sporozoite-

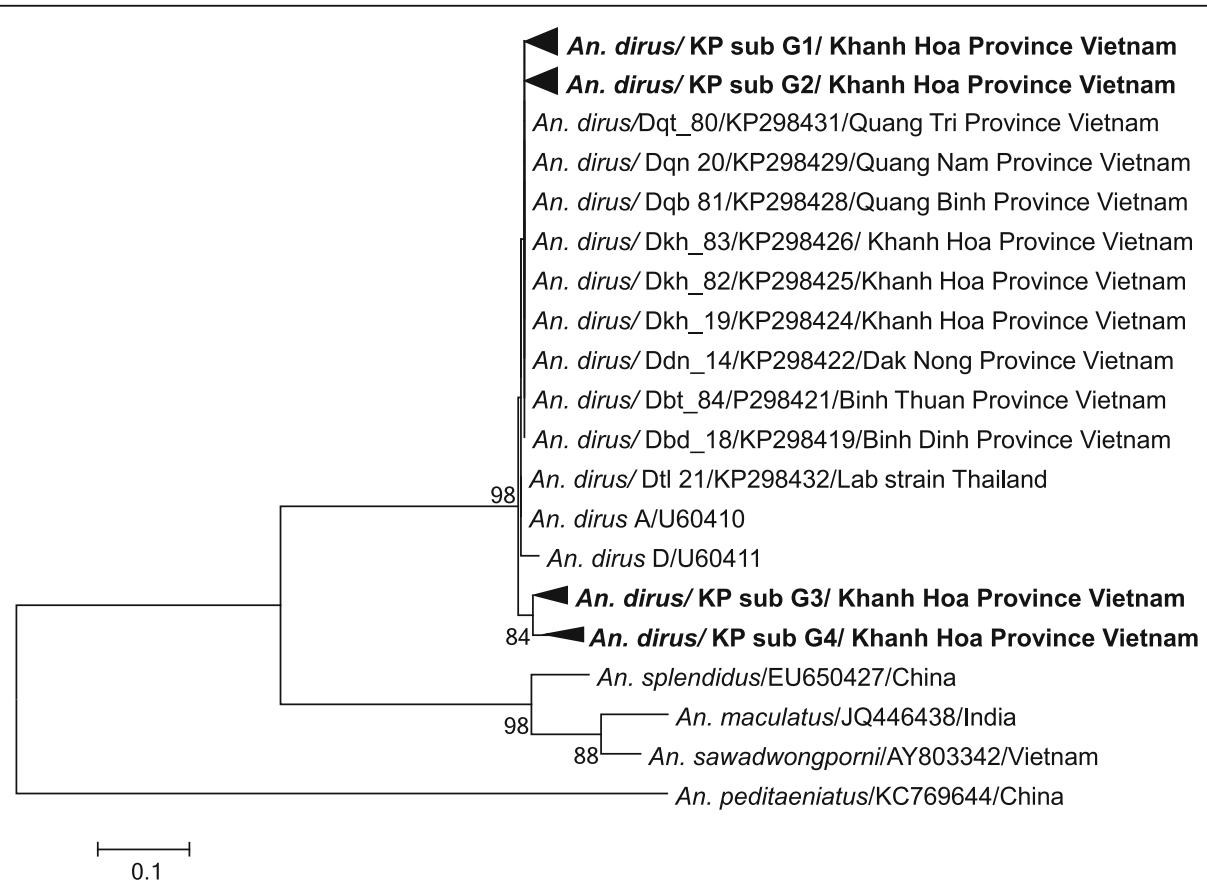

Fig. 1 Molecular phylogenetic analysis of Anopheles dirus in Khanh Phu commune (KP subgroup 1, 2, 3 and 4) by maximum likelihood methodology. The evolutionary history was inferred by using the Maximum Likelihood method based on the Tamura-Nei model. The percentage of trees in which the associated taxa clustered together is shown next to the branches. Bootstrap values of $<80 \%$ are not shown. The scale-bar indicates the expected number of substitutions per nucleotide. Evolutionary analyses were conducted in MEGA6 
Table 1 Results of the collections and dissections of Anopheles dirus mosquitoes caught by human landing catch in the study area

\begin{tabular}{|c|c|c|c|c|c|c|c|}
\hline Year & Period & No. caught & No. nights & Biting density $^{a}$ & No. dissected & No. sporozoites & $\%$ \\
\hline 2008 & Jan to Dec & 2120 & 724 & 2.9 & 2119 & 22 & 1.0 \\
\hline 2009 & Jan to Dec & 2856 & 676 & 4.2 & 2848 & 32 & 1.1 \\
\hline 2010 & Jan to Dec & 3218 & 674 & 4.8 & 3207 & 77 & 2.4 \\
\hline 2011 & Jan to Dec & 1601 & 659 & 2.4 & 1594 & 21 & 1.3 \\
\hline 2012 & Jan to Oct & 1669 & 563 & 3.0 & 1669 & 16 & 1.0 \\
\hline Total & & 11,464 & 3296 & 3.5 & 11,437 & 168 & 1.5 \\
\hline
\end{tabular}

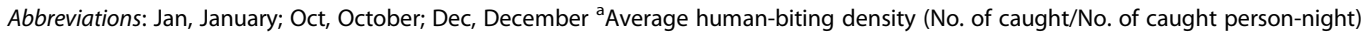

positive samples analysed (15\%). Of these samples, one was found to be a co-infection of wild type and mutant alleles, and the other four were single genotype mutant alleles. These five-mutant allele-positive samples were captured in March and April 2009 and 2010, and no mutant alleles were observed from mosquitoes captured at other times (Table 3). Samples containing mutant alleles were captured both in the forest and at the forest fringe. Three mutant samples were observed in $P$. falciparum single species infections, and two were found in P. falciparum infections co-infecting mosquito salivary glands with other malaria parasite species (Table 3).

The prevalence of malaria in the study area has declined sharply since 1998 and was considered to be 'residual forest malaria' during the study period, while the proportion of $P$. falciparum among infections has remained substantial; densities of $A n$. dirus typically peak in March and April [11]. The sample sizes of $P$. falciparum infections analyzed for K13 from 2008 to 2012 (Table 2) preclude analysis of prevalence trends through time.

There have been no previous reports of ARTresistance associated mutations in the Pfk13 gene from this region of Vietnam. We observed only an azygous non-synonymous mutation in Pfk13, P553L, and this was present at low frequencies. This mutant allele has been identified previously, in samples collected from the Vietnam-Cambodia border, Southern China and Kenya [10, 16-19]. It is not currently known whether it is linked resistance to ART [8].

The Vietnamese national malaria treatment guidelines proscribe that patients are treated with $2.4 \mathrm{mg} /$ $\mathrm{kg}$ of body weight dihydroartemisinin and $18 \mathrm{mg} / \mathrm{kg}$ piperaquine once a day for 3 days, and these guidelines were in effect in Khanh Hoa province during this study. The first record of the protracted parasite clearance after treatment with artesunate monotherapy or dihydroartemisinin-piperaruine was from the $\mathrm{Bu}$ Dang district of Binh Phuoc province in 2009 [20]. In that area, five types of mutant allele, including P553L, have been found Pfk13 [10]. Our study demonstrates the presence of the Pfk13 P553L SNP in 2009 and 2010 in Khanh Hoa province, some 200 km distant from Binh Phuoc. This result could suggest that the parasite populations of Southcentral Vietnam are contiguous over large distances, and that mutant allele gene flow is possible between relatively distant regions, although more evidence is required to support this hypothesis.

\section{Conclusions}

In conclusion, this study demonstrates the presence of mono non-synonymous nucleotide mutations in the Pfk13 gene in P. falciparum sporozoites isolated from the salivary glands of from An. dirus. The

Table 2 Prevalence of Plasmodium falciparum and analysis of K13 propeller gene of sporozoites in Anopheles dirus mosquitoes

\begin{tabular}{|c|c|c|c|c|c|}
\hline Year & No. examined samples & P. falciparum & K13 gene analyzed & Wild type $(\%)^{a}$ & Mutation type (\%) ${ }^{\mathrm{a}}$ \\
\hline 2008 & 7 & 2 & 2 & 2 & 0 \\
\hline 2009 & 31 & 14 & 13 & 9 & 4 \\
\hline 2010 & 77 & 23 & 15 & 14 & 1 \\
\hline 2011 & 21 & 3 & 3 & 3 & 0 \\
\hline 2012 & 16 & 0 & 0 & 0 & 0 \\
\hline Total & 152 & 42 & 33 & $28(84.8)$ & $5(15.2)$ \\
\hline
\end{tabular}

Wild type (or mutation type) / K13 gene analysed 
Table 3 Mutant alleles of Pfk13 in Plasmodium falciparum sporozoites from Anopheles dirus mosquitoes

\begin{tabular}{|c|c|c|c|c|c|c|c|}
\hline \multirow[t]{2}{*}{ ID } & \multirow[t]{2}{*}{ Year } & \multirow{2}{*}{$\begin{array}{l}\text { Collected } \\
\text { date }\end{array}$} & \multirow{2}{*}{$\begin{array}{l}\text { Parasite } \\
\text { species }\end{array}$} & \multicolumn{3}{|l|}{ Nonsynymous } & \multirow{2}{*}{$\begin{array}{l}\text { Synonymous } \\
\text { Genetic change }\end{array}$} \\
\hline & & & & Amino acid change and location & Genetic change & Captured site & \\
\hline 70701 & 2009 & 3 March & Pf & P553L & $\mathrm{CCG} \rightarrow \mathrm{CTG}$ & Forest fringe & None \\
\hline 70752 & 2009 & 6 March & Pf & P553L & $\mathrm{CCG} \rightarrow \mathrm{CTG}$ & Forest fringe & None \\
\hline 70926 & 2009 & 15 March & $P f+P k+P i n u$ & P553L & $\mathrm{CCG} \rightarrow \mathrm{CTG}$ & Forest fringe & None \\
\hline 71308 & 2009 & 3 April & Pf + Pcoat & P553L & $\mathrm{CCG} \rightarrow \mathrm{CTG}$ & In the forest & None \\
\hline 76280 & 2010 & 9 April & $P f+P v+P i n u$ & P553L + Wild & $\mathrm{CCG} \rightarrow \mathrm{CTG}$, None & In the forest & None \\
\hline
\end{tabular}

Abbreviations: Pf, P. falciparum; Pv, P. vivax; Pk, P. knowlesi; Pinu, P. inui; Pcoat, P. coatneyi

observed mutant allele, P553L, has previously been reported in a different region of Vietnam. No other mutant alleles, including those previously recorded in Vietnam were found in this study area.

Our results show that mosquito stage malaria parasites are a useful source of parasite DNA for drug-resistance associated molecular epidemiological studies.

\section{Acknowledgments}

Phan Chau Do, Nguyen Son Hai, Dang Duy Vu and Nguyen Le Dung are thanked for their technical support. The Provincial Health Service and Malaria Control Centre of Khanh Hoa Province and the authorities of Khanh Vinh district and Khanh Phu municipality provided administrative support.

\section{Funding}

This study was supported in part by the following three grants: (i) JSPS KAKENHI Grant Number 26360029 and 17H04513, (ii) a Grant-in-Aid for Scientific Research from Fujita Health University, (iii) the Cooperative Research Grants from Joint Usage / Research Center on Tropical Disease, Institute of Tropical Medicine, Nagasaki University (2015-Ippan-14, 2016-Ippan-9). The Khanh Phu Malaria Research team and the field research costs were financially supported through private donations to the Medical Committee Netherlands-Vietnam.

\section{Availability of data and materials}

The data supporting the conclusions of this article are included within the article. Nucleotide sequences generated in this work have been deposited at GenBank, accession numbers MF326505-MF326508.

\section{Authors' contributions}

Conceived and designed the study: YM, SN, NTQ and RPM. Field work and data collection performed by: GM, NTQ and RPM. Experiments performed by: YM, KH, RC, SK and SN. Wrote the paper: YM, SN, SK, RC, RPM, NTQ, KH and GM. All authors read and approved the final manuscript.

\section{Competing interests}

The authors declare that they have no competing interests.

\section{Consent for publication}

Not applicable.

\section{Ethics approval and consent to participate}

This study was certified as permitted standard procedures by the National Institute of Malariology, Parasitology and Entomology in Hanoi, and was reviewed and approved by the ethics committees of Institute of Tropical Medicine, Nagasaki University (permit number: 10121662-5). Mosquito collectors provide informed consent.

\section{Publisher's Note}

Springer Nature remains neutral with regard to jurisdictional claims in published maps and institutional affiliations.

\begin{abstract}
Author details
${ }^{1}$ Department of Virology and Parasitology, Fujita Health University School of Medicine, Toyoake, Aichi, Japan. ${ }^{2}$ Khanh Phu Malaria Research Unit, Medical Committee Netherlands-Viet Nam, Nha Trang, Khanh Hoa province, Viet Nam. ${ }^{3}$ Malaria Unit, Department of Pathology, Institute of Tropical Medicine, Nagasaki University, Nagasaki, Japan. ${ }^{4}$ Laboratory of Tropical Medicine and Parasitology, Dokkyo Medical University, Mibu, Tochigi, Japan. ${ }^{5}$ Faculty of International Liberal Arts, Juntendo University, Tokyo, Japan. ${ }^{6}$ Department of Protozoology, Institute of Tropical Medicine, Nagasaki University, Nagasaki, Japan.
\end{abstract}

Received: 28 December 2016 Accepted: 15 June 2017

Published online: 24 June 2017

\section{References}

1. Noedl H, Se Y, Schaecher K, Smith BL, Socheat D, Fukuda MM. Artemisinin resistance in Cambodia 1 ( $A R C 1$ ) study consortium. Evidence of artemisininresistant malaria in western Cambodia. N Engl J Med. 2008;359(24):2619-20. doi:10.1056/NEJMc0805011.

2. Dondorp AM, Nosten F, Yi P, Das D, Phyo AP, Tarning J, et al. Artemisinin resistance in Plasmodium falciparum malaria. N Engl J Med. 2009;361(5):45567. doi:10.1056/NEJMoa0808859. Erratum in: N Engl J Med. 2009;361(17): 1714

3. Amaratunga C, Sreng S, Suon S, Phelps ES, Stepniewska K, Lim P, et al. Artemisinin-resistant Plasmodium falciparum in Pursat province, western Cambodia: a parasite clearance rate study. Lancet Infect Dis. 2012;12(11): 851-8.

4. Phyo AP, Nkhoma S, Stepniewska K, Ashley EA, Nair S, McGready R, et al. Emergence of artemisinin-resistant malaria on the western border of Thailand: a longitudinal study. Lancet. 2012;379(9830):1960-6.

5. Kyaw MP, Nyunt MH, Chit K, Aye MM, Aye KH, Aye MM, et al. Reduced susceptibility of Plasmodium falciparum to artesunate in southern Myanmar. PLoS One. 2013:8(3):e57689.

6. Ashley EA, Dhorda M, Fairhurst RM, Amaratunga C, Lim P, Suon S, et al. Tracking resistance to artemisinin collaboration (TRAC). Spread of artemisinin resistance in Plasmodium falciparum malaria. N Engl J Med. 2014;371(5):411-23. Erratum in: N Engl J Med. 2014;371(8):786.

7. Lu F, Culleton R, Zhang M, Ramaprasad A, von Seidlein L, Zhou H, et al. Emergence of indigenous artemisinin-resistant Plasmodium falciparum in Africa. N Engl J Med. 2017;376(10):991-3.

8. Takala-Harrison S, Clark TG, Jacob CG, Cummings MP, Miotto O, Dondorp AM, et al. Genetic loci associated with delayed clearance of Plasmodium falciparum following artemisinin treatment in Southeast Asia. Proc Natl Acad Sci USA. 2013:110(1):240-5

9. Ariey F, Witkowski B, Amaratunga C, Beghain J, Langlois AC, Khim N, et al. A molecular marker of artemisinin-resistant Plasmodium falciparum malaria. Nature. 2014:505(7481):50-5.

10. Takala-Harrison S, Jacob CG, Arze C, Cummings MP, Silva JC, Dondorp AM, et al. Independent emergence of artemisinin resistance mutations among Plasmodium falciparum in Southeast Asia. J Infect Dis. 2015;211(5):670-9.

11. Marchand RP, Culleton R, Maeno Y, Quang NT, Nakazawa S. Co-infections of Plasmodium knowlesi, P. falciparum, and P. vivax among humans and Anopheles dirus mosquitoes, Southern Vietnam. Emerg Infect Dis. 2011;17(7): 1232-9.

12. Maeno Y, Quang NT, Culleton R, Kawai S, Masuda G, Nakazawa S, et al. Humans frequently exposed to a range of non-human primate malaria 
parasite species through the bites of Anopheles dirus mosquitoes in Southcentral Vietnam. Parasit Vectors. 2015;8:376.

13. Vietnam National Institute of Malariology, Parasitology and Entomology. Identification key for Anophelinae in Vietnam. Hanoi: Medical Publishing House; 2008.

14. Nakazawa S, Marchand RP, Quang NT, Culleton R, Manh ND, Maeno Y. Anopheles dirus co-infection with human and monkey malaria parasites in Vietnam. Int J Parasitol. 2009;39(14):1533-7.

15. Singh B, Bobogare A, Cox-Singh J, Snounou G, Abdullah MS, Rahman HA. A genus- and species-specific nested polymerase chain reaction malaria detection assay for epidemiologic studies. Am J Trop Med Hyg. 1999;60: 687-92.

16. Boussaroque A, Fall B, Madamet M, Camara C, Benoit N, Fall M, et al. Emergence of mutations in the K13 propeller gene of Plasmodium falciparum isolates from Dakar, Senegal, in 2013-2014. Antimicrob Agents Chemother.

17. Huang F, Takala-Harrison S, Jacob CG, Liu H, Sun X, Yang H, et al. A single mutation in K13 predominates in southern China and is associated with delayed clearance of Plasmodium falciparum following artemisinin treatment. J Infect Dis. 2015;212(10):1629-35.

18. Leang R, Taylor WR, Bouth DM, Song L, Tarning J, Char MC, et al. Evidence of Plasmodium falciparum malaria multidrug resistance to artemisinin and piperaquine in Western Cambodia: dihydroartemisinin-piperaquine openlabel multicenter clinical assessment. Antimicrob Agents Chemother. 2015; 59(8):4719-26.

19. Taylor SM, Parobek CM, DeConti DK, Kayentao K, Coulibaly SO, Greenwood $\mathrm{BM}$, et al. Absence of putative artemisinin resistance mutations among Plasmodium falciparum in sub-Saharan Africa: a molecular epidemiologic study. J Infect Dis. 2015;211(5):680-8.

20. Update on artemisinin and ACT resistance-September 2015. Geneva: World Health Organization, September; 2015. http://www.who.int/malaria/ publications/atoz/status-rep-artemisinin-act-resistance-sept2015.pdf?ua=1 WHO/HTM/GMP/2015.4. Accessed 15 Nov 2016.

\section{Submit your next manuscript to BioMed Central and we will help you at every step:}

- We accept pre-submission inquiries

- Our selector tool helps you to find the most relevant journal

- We provide round the clock customer support

- Convenient online submission

- Thorough peer review

- Inclusion in PubMed and all major indexing services

- Maximum visibility for your research

Submit your manuscript at www.biomedcentral.com/submit 